\title{
A resolução de problemas e a experimentação investigativa nas orientações curriculares para o ensino fundamental e médio no Brasil
}

\author{
The problem solving and the investigative experimentation in the curricular \\ guidelines for the elementary and middle school in Brazil
}

\section{La resolución de problemas y la experimentación investigativa en las orientaciones curriculares para la enseñanza primaria y secundaria en Brasil}

\author{
João Manoel da Silva Malheiro² \\ Odete Pacubi Baierl Teixeira ${ }^{3}$
}

\begin{abstract}
Resumo: Neste artigo, objetivamos discutir os princípios gerais propostos pelo Ministério da Educação do Brasil, com relação à experimentação e à resolução de problemas que constam nas Orientações Curriculares para o Ensino Fundamental e Médio nos domínios das Ciências/Biologia (BRASIL, 1997a; 1997b; 2002; 2006). Nesse contexto, definimos nossa pesquisa como estudo de caso, pois realizamos pesquisa documental a partir de diplomas oficiais. A partir das análises das ideias presentes nos documentos, acreditamos que as práticas pedagógicas possivelmente se manterão longe das Orientações Curriculares, pois os docentes não são meros executores de políticas educacionais, mas reinterpretam-nas, adaptando-as de acordo com as suas vivências, interesses e valores.
\end{abstract}

Palavras-chave: Orientações curriculares. Experimentação e resolução de problemas. Ensino de ciênciasbiologia.

\begin{abstract}
In this article, we aim to discuss the general principles proposed by the Brazilian Ministry of Education, with respect to experimentation and problem solving which are contained in the Curricular Guidelines for Elementary and Middle School in the fields of Science/Biology (BRASIL, 1997a; 1997b; 2002; 2006). In this context, we define our research as a case study because we conduct documentary research based on official diplomas. From the analyzes of the ideas present in the documents, we believe that the pedagogical practices will possibly be kept away from the Curricular Guidelines, because teachers are not mere executors of educational policies, but reinterpret them, adapting them according to their experiences, interests and values.
\end{abstract}

Keywords: Curricular guidelines. Experimentation and problem solving. Teaching of sciences-biology.

Resumen: En este artículo, el objetivo es discutir los principios generales propuestos por el Ministerio de Educación de Brasil, con relación a la experimentación y la resolución de problemas que constan en las orientaciones curriculares para la enseñanza primaria y secundaria en los dominios de la ciencias/biologías (BRASIL, 1997a; 1997b; 2002; 2006). En este contexto, definimos nuestra investigación como estudio de caso, pues realizamos una búsqueda documental a partir de los diplomas oficiales. A partir de los análisis de las ideas presentes en los documentos, creemos que las prácticas pedagógicas posiblemente se mantendrán lejos de las orientaciones curriculares, pues los docentes no son meros ejecutores de políticas educacionales, pero reinterpretamos y nos adaptamos de acuerdo con sus vivencias, intereses y valores.

Palabras clave: Orientaciones curriculares. Experimentación y resolución del problema. Enseñanza de cienciabiología.

\footnotetext{
${ }^{1}$ Submetido em: 28 jun. 2018 - Aceito em: 01 jul. 2019 - Publicado em: 20 dez. 2019

${ }^{2}$ Universidade Federal do Pará (UFPA) - E-mail: joaomalheiro@ufpa.br

${ }^{3}$ Universidade Estadual Paulista (UNESP) - E-mail: opbt@feg.unesp.br
} 


\section{Introdução}

Em 1997, quando o governo brasileiro apresentou para a comunidade docente os Parâmetros Curriculares Nacionais (PCN) para o Ensino Fundamental e Médio, objetivava implementar um novo arranjo curricular, na esperança que, a pari passu, novas ações metodológicas pudessem se incorporar às práticas pedagógicas dos professores (RICARDO; ZYLBERSZTAJN, 2007).

Sem dúvida, que os PCN provocaram reações diversas entre os professores, que estabeleceram críticas severas aos documentos, não só na esfera política (no que diz respeito ao momento de transformações que o Brasil vivia naquela ocasião), mas na perspectiva de que, muitos professores (principalmente dos lugares mais longínquos do Brasil) não foram ouvidos acerca do documento (RICARDO; ZYLBERSZTAJN, 2002).

Nessa perspectiva, tanto os Parâmetros Curriculares Nacionais (Ciências Naturais) (BRASIL, 1997a), quanto os PCN + Ensino Médio (BRASIL, 2002), não tiveram a repercussão esperada pelo Ministério da Educação (MEC) no âmbito da Educação Básica. Muitos professores acabaram não tendo a oportunidade de realizar uma leitura de forma a refletir sobre os referidos documentos. Claramente essa situação traz à tona a ausência

de políticas educacionais que viabilizassem tais discussões acompanhadas de formação continuada e de ações efetivas para modificar a estrutura escolar ainda centralizadora e apoiada em cargas horárias pesadas para os docentes, cujas práticas se resumem em ministrar aulas (RICARDO; ZYLBERSZTAJN, 2007, p. 2).

Diante desse cenário, discussões pertinentes acerca da importância dos professores de Ciências e de Biologia adequarem suas aulas à perspectiva da resolução de problemas e da experimentação, que estão explícitas nesses documentos oficiais (BRASIL, 1997a; 1997b; 2002), não foram adequadamente compreendidas por grande parte dos docentes (MALHEIRO, 2009).

Concordamos com Lopes (1994, p. 24), quando considera que os "verdadeiros" problemas são, em geral, uma situação em que ainda não se conhece a resposta, tampouco sabemos se ela realmente existe; há uma forma muito distinta dos chamados problemas de lápis e papel e "podem ter diferentes níveis de dificuldade e complexidade".

Nessa perspectiva, a resolução de problemas poderá assumir um papel central no ensino de Ciências e Biologia. Mas, para que isso aconteça, deverá ter características próprias, particularizadas pelo ano/série que os estudantes estiverem cursando e sempre correspondendo aos objetivos do ensino e da aprendizagem previstos para aquele ano (MALHEIRO, 2009).

Apesar dessa visão dos pesquisadores, é importante ressaltar a necessidade de compreendermos que a noção de "problema" vai depender, principalmente, da perspectiva teórica, do contexto problemático e dos métodos de abordagem levados a cabo pelo professor. A junção desses três fatores (além de outros) poderá definir mais abertamente o que o docente considera como um problema (MALHEIRO, 2009). 
Com relação ao que assumimos nesta pesquisa como experimentação investigativa, comungamos com as considerações de Almeida (2017, p. 44) quando assevera que

\begin{abstract}
Na escola, a experimentação é um processo que permite ao aluno se envolver com o conteúdo em estudo, levantar hipóteses, procurar alternativas, avaliar resultados, bem como participar das descobertas e socializações com seus pares. Desta forma, as atividades experimentais possuem um caráter motivador, promovendo o raciocínio, a reflexão, a construção do conhecimento e uma melhor compreensão das etapas de ação das ciências.
\end{abstract}

Nesse sentido, confiamos que o professor deverá valorizar os caminhos percorridos pelos estudantes durante a experimentação investigativa realizada para a resolução de um problema e não apenas os resultados advindos deles, pois mais importante que conhecer a solução do problema é saber como encontrá-la (LORENZATO, 2010).

Desse modo, esta pesquisa de análise documental objetiva discutir os princípios norteadores sugeridos pelo MEC aos professores de Ciências e Biologia, com relação à efetivação da experimentação e da resolução de problemas, na perspectiva de dinamizar as aulas, em busca de um entendimento mais contextualizado dos conteúdos por parte dos estudantes.

Assim, para que nossos objetivos fossem alcançados, organizamos esse artigo no sentido de, inicialmente, apresentarmos ao leitor o Percurso Metodológico, onde procuramos definir a abordagem metodológica utilizada e os referenciais assumidos para caracterizar nossa pesquisa dentro das configurações pertinentes a uma pesquisa científica documental proposta a partir da perspectiva de um estudo de caso, elegendo como categorias de análise as palavras resolução de problemas e experimentação. Em seguida, com base nessas categorias, procuramos trazer à discussão e análise recortes dos documentos oficiais na área das Ciências e Biologia (BRASIL, 1997a; 1997b; 2002; 2006), onde essas palavras foram citadas.

Por fim, apresentamos as Considerações Finais, quando procuramos destacar os fundamentos analíticos alcançados, no sentido de permitir ao leitor interpretar se, com base nas informações contidas nos documentos, os professores de Ciências e Biologia têm as informações necessárias para implementarem com êxito a metodologia da Resolução de Problemas e Experimentação Investigativa em suas aulas.

\title{
Percurso metodológico
}

Considerando que a escolha da metodologia deve ser realizada tomando por base a natureza da questão de pesquisa (DENZIN; LINCOLN, 2006), que nesse estudo objetiva “discutir os princípios gerais propostos pelo Ministério da Educação, com relação à experimentação e à resolução de problemas que constam nas Orientações Curriculares para o Ensino Fundamental e Médio nos domínios das Ciências/Biologia”, avaliamos pertinente lançar mão de uma pesquisa qualitativa ou interpretativa, pois consideramos mais apropriada para análise documental (SILVA, 2010). 
Após leitura criteriosa dos documentos oficiais (BRASIL, 1997a; 1997b; 2002; 2006), elegemos como categorias para uma análise interpretativa os trechos dos documentos em que os termos experimentação e resolução de problemas são citados. A partir do momento em que essas palavras foram identificadas, passamos a fazer uma aproximação teórica entre os pesquisadores que discutem essas metodologias e a forma como estão abordadas nesses documentos.

Deste modo, ao analisar os diplomas que constam as Orientações Curriculares (BRASIL, 1997a; 1997b; 2002; 2006), nos atentamos, especificamente, para o entendimento e a interpretação acerca de como as expressões experimentação e resolução de problemas são abordadas no texto oficial e de que forma poderiam ser descritas para uma melhor compreensão dos professores (SERRANO, 2004). "Assim, em investigação qualitativa a teoria surge a partir da recolha, análise, descrição e interpretação dos dados" (SILVA, 2010, p. 117).

A opção pelo estudo de caso para melhor dar conta da questão norteadora desta pesquisa, fundamenta-se no fato de nesse estudo ser mais importante o aprofundamento das perspectivas anunciadas nos documentos oficiais com relação à experimentação e à resolução de problemas, do que à extensão que essas expressões possam suscitar nos professores. Portanto, a atenção está voltada mais para o processo do que para as implicações, mais para o conjunto do que para uma variável específica (MERRIAM, 1998).

Nessa perspectiva, consideramos relevante definir a pesquisa como estudo de caso porque, acreditamos que

os discursos curriculares resultam de processos de negociação e de articulação entre a produção de dispositivos legais, a produção de documentos curriculares e o trabalho dos professores e que, nesta circularidade, este último contexto, o da prática, é sempre condicionado pelos outros, mas ele próprio é produtor de novos sentidos (SILVA, 2010, p. 119, grifos da autora).

Além dessa dimensão, o estudo de caso possibilita, por um lado, olhar com mais acuidade e amplitude múltiplos aspectos da questão de pesquisa, além das possíveis concepções e perspectivas teóricas implícitas nas letras dos documentos e suas possíveis relações para a melhoria da prática pedagógica dos professores de Ciências e Biologia.

Por outro lado, recorrer aos documentos oficiais tem relação direta com os fundamentos definidores de um estudo de caso. Deste modo, a pesquisa documental é considerada por muitos pesquisadores qualitativos, como um dos procedimentos mais recorrentes de ser utilizado individualmente na análise de dados ou concomitante com outras técnicas de recolha de informações (BOGDAN; BIKLEN, 1994).

Nesse sentido, os documentos oficiais, ao serem considerados como fontes de informação, são denominados de dados ou informações secundárias (VALLES, 1997), já que não dizem respeito aos dados diretamente organizados e produzidos por pesquisadores para fins de investigação (SILVA, 2010). Destarte, podemos constatar que os documentos oficiais são originários de propósitos diferentes dos de uma investigação. 
Neste estudo, como já apontado anteriormente, elegemos para a análise os seguintes documentos: Parâmetros Curriculares Nacionais (Ciências da Natureza) (BRASIL, 1997a), Parâmetros Curriculares Nacionais (Ensino Médio - Parte III: Ciências da Natureza, Matemática e suas Tecnologias) (BRASIL 1997b), Parâmetros Curriculares Nacionais + Ensino Médio (Orientações Educacionais Complementares aos Parâmetros Curriculares Nacionais, Ciências da Natureza, Matemática e suas Tecnologias) (BRASIL, 2002) e Orientações Curriculares para o Ensino Médio (Ciências da Natureza, Matemática e suas Tecnologias) (BRASIL, 2006).

Portanto, a partir dos documentos oficiais apresentados anteriormente, bem como os fundamentos que definem a pesquisa qualitativa na perspectiva do estudo de caso, por meio da análise de documentos oficiais norteadores para uma possível prática pedagógica dos professores (VALLES, 1997; SILVA, 2010), direcionamos nosso olhar para os trechos dos documentos em que destacam as expressões experimentação e resolução de problemas, para analisar de que forma os professores podem redimensionar suas práticas.

\section{A resolução de problemas (RP) e a experimentação: análise e discussão}

Com base nos Parâmetros Curriculares Nacionais para o Ensino Fundamental (EF) e Ensino Médio (EM), pontuamos algumas orientações propostas pelo Ministério da Educação no que diz respeito, particularmente, ao ensino de Ciências e Biologia, em relação à resolução de problemas e à experimentação.

A resolução de problemas e a experimentação nas Orientações Curriculares Nacionais para a Educação Básica

No final dos anos 1990, o Ministério da Educação (BRASIL, 1997a), publicou os Parâmetros Curriculares Nacionais. Ao enfocar a necessidade de se ensinar Ciências Naturais no Ensino Fundamental, os PCN destacam o valor de se "mostrar a Ciência como um conhecimento que colabora para a compreensão do mundo e suas transformações, para reconhecer o homem como parte do universo e como indivíduo" (BRASIL, 1997a, p. 21).

Além desse aspecto, Krasilchik (2008), destaca que os PCN buscavam também definir um currículo que pudesse ser trabalhado por todos os professores de Ciências do Brasil. Apesar de esse fato estar implícito no documento, seus formuladores afirmam não se tratar de proposição de um currículo homogêneo e impositivo, mas de uma sugestão inovadora que pudesse redirecionar o ensino de Ciências com vista a tornar a aprendizagem contextualizada, desenvolvendo nos estudantes habilidades e competências que são essenciais para a sua vida em sociedade.

Baseado nesses princípios norteadores do currículo, os PCN (BRASIL, 1997a), deixam claro que nos objetivos gerais das Ciências Naturais para o Ensino Fundamental definidos no documento, a problematização e a experimentação ganham destaque, quando 
salientam que "[...] Formular questões, diagnosticar e propor soluções para problemas reais a partir de elementos das Ciências Naturais, colocando em prática conceitos, procedimentos e atitudes desenvolvidos no aprendizado escolar" (BRASIL, 1997a, p. 31, grifos nossos), são propósitos a serem alcançados ao final das aulas de Ciências.

Do mesmo modo, o documento destaca que os estudantes devem “[...] Saber combinar leituras, observações, experimentações, registros, etc., para coleta, organização, comunicação e discussão de fatos e informações (BRASIL, 1997a, p. 31, grifos nossos).

No mesmo sentido, os Parâmetros Curriculares Nacionais procuram particularizar a importância dos objetivos das Ciências Naturais no primeiro ciclo do Ensino Fundamental (BRASIL, 1997a, p. 47, grifos nossos), quando consideram fundamental que os alunos possam "realizar experimentos simples sobre os materiais e objetos do ambiente para investigar características e propriedades dos materiais e de algumas formas de energia". Mais adiante, sobreleva a obrigação do estudante "formular perguntas e suposições sobre o assunto em estudo" (BRASIL, 1997a, p. 47, grifos nossos).

Podemos perceber que, de um modo geral, o documento almeja mostrar ao professor a necessidade de planejar e executar aulas de Ciências que possam promover nos estudantes a capacidade de formular perguntas, indagar, levantar, testar e analisar as hipóteses por eles propostas e decidir sobre qual caminho seguir em direção à resolução do problema (MALHEIRO, 2016).

Com relação aos objetivos apontados para o segundo ciclo do Ensino Fundamental, o documento novamente dá ênfase à necessidade da retomada da experimentação e da resolução de problemas, além de ser capaz de "buscar e coletar informações por meio da observação direta e indireta, da experimentação, de entrevistas e visitas, conforme requer o assunto em estudo e sob orientação do professor" (BRASIL, 1997a, p. 58, grifos nossos).

Percebemos, pelas questões recomendadas no documento, que a experimentação investigativa para a resolução de um problema, apresenta-se como uma possibilidade real que pode contribuir para os professores de Ciências redimensionarem sua prática, no sentido de mostrar aos estudantes, que os conhecimentos científicos podem ser assimilados de diversas formas e meios, bastando para isso que tenham um olhar atento ao seu redor (FRANCISCO JÚNIOR; FERREIRA; HARTWIG, 2008).

\section{Orientações didáticas para o trabalho docente no ensino fundamental}

No que se refere às "Orientações Didáticas" para o trabalho docente, os PCN (BRASIL, 1997a, p. 77, grifos nossos) evidenciam a problematização como uma das prioridades a serem consideradas pelos professores de Ciências. Esse processo de problematizar os conhecimentos deve ter como ponto de partida a vivência dos alunos na comunidade em que estão inseridos.

Diante deste fato, 
o professor poderá promover a desestabilização dos conhecimentos prévios, criando situações em que se estabeleçam os conflitos necessários para a aprendizagem [...] Coloca-se, assim, um problema para os alunos, cuja solução passa por coletar novas informações, retomar seu modelo e verificar o limite dele (BRASIL, 1997a, p. 77).

É a partir dos conhecimentos prévios dos estudantes, que os professores necessitam tomar como referência para a proposição de problemas (ROSITO, 2008). Vale ressaltar que os alunos só se sentirão desafiados para resolverem o problema a partir do momento em que perceberem que o mesmo é interessante e desafiador. Além disso, muitas vezes os estudantes percebem que os seus conhecimentos prévios, não foram suficientes para elucidar o caso. Desta forma, "uma questão toma a dimensão de um problema quando suscita a dúvida, estimula a solução e cria a necessidade de ir em busca de informações" (BRASIL, 1997a, p. 83). Posteriormente, orientados pelo professor, os educandos estarão aptos a seguir novos rumos investigativos no sentido de perseguir o encaminhamento da solução do problema.

Mais adiante, o documento dá ênfase ainda à importância de ressignificar os procedimentos experimentais na escola. Os PCN destacam que o trabalho docente deve dar novo sentido aos protocolos ou guias de experimentos, principalmente quando os mesmos são apresentados aos alunos como um modelo fixo, a-histórico e descontextualizado de sentido lógico. Apontam a exigência de os mesmos serem realizados

pelos alunos quando discutem idéias e manipulam materiais. Ao lhes oferecer um protocolo definido ou guia de experimento, os desafios estão em interpretar o protocolo, organizar e manipular os materiais, observar os resultados e checá-los com os esperados (BRASIL, 1997a, p. 80).

Além desse novo enfoque que os docentes devem dar aos protocolos, os PCN anunciam ainda a importância de permitir que os discentes construam os próprios experimentos. Nesse caso, a atuação do professor será no sentido de discutir com os mesmos a definição do problema, e a relação dos materiais que serão utilizados durante a testagem das hipóteses levantadas, além de discutir sobre a maneira de coletar os dados e relacioná-los aos resultados previstos inicialmente.

\section{A resolução de problemas e a experimentação nas Orientações Curriculares Nacionais para o Ensino Médio}

Com relação ao Ensino Médio, os Parâmetros Curriculares Nacionais para o Ensino Médio (PCNEM), particularmente para as Ciências Naturais, Matemática e suas Tecnologias (BRASIL, 1997b), também dão destaque em seu texto à experimentação e/ou à resolução de problemas, bem como o desenvolvimento da capacidade de comunicação. Os PCNEM ressaltam que os estudantes deverão:

produzir textos adequados para relatar experiências, formular dúvidas ou apresentar conclusões [...]; Identificar variáveis relevantes e selecionar os procedimentos necessários para a produção, análise e interpretação de resultados de processos e experimentos científicos e tecnológicos (BRASIL, 1997b, p. 12, grifos nossos).

Destacamos também aquelas que preveem que o aluno seja capaz de: 
Formular questões a partir de situações reais e compreender aquelas já enunciadas; [...]. Procurar e sistematizar informações relevantes para a compreensão da situação-problema; Formular hipóteses e prever resultados; Elaborar estratégias de enfrentamento das questões; Interpretar e criticar resultados a partir de experimentos e demonstrações (BRASIL, 1997b, p. 12, grifos nossos).

É notório que, apesar das competências e habilidades estarem relacionadas à todas as disciplinas que compõem a área das Ciências da Natureza e Matemática, tacitamente podemos constatar que tanto a experimentação quanto a resolução de problemas são consideradas estratégias de ensino que transcendem a área dessas Ciências e podem ser utilizadas por outras áreas do conhecimento.

Além da importância de os estudantes desenvolverem a capacidade de comunicação das ações que realizam no ambiente escolar (ou fora dele), o documento (BRASIL, 1997b) também enfatiza as competências e habilidades referentes à Investigação e Compreensão, bem como à Representação e Comunicação, destacando que as mesmas são habilidades em que a resolução de situações problemáticas e a utilização dos procedimentos experimentais são mais necessárias de serem desenvolvidas pelos educandos como, quando cogitam que os mesmos devem:

\footnotetext{
Apresentar suposições e hipóteses acerca dos fenômenos biológicos em estudo; [...] Conhecer diferentes formas de obter informações (observação, experimento, leitura de texto e imagem, entrevista), selecionando aquelas pertinentes ao tema biológico em estudo. [...] Selecionar e utilizar metodologias científicas adequadas para a resolução de problemas, fazendo uso, quando for o caso, de tratamento estatístico na análise de dados coletados. [...] Formular questões, diagnósticos e propor soluções para problemas apresentados, utilizando elementos da Biologia (BRASIL, 1997b, p. 21, grifos nossos).
}

Com as referências mencionadas, buscamos refletir sobre a necessidade de os professores de Ciências e Biologia aprofundarem os estudos e as discussões sobre as possibilidades de transmudar as ideias impressas no papel para as salas de aula. Porém, para que isso se torne realidade, como considera Gaspar (2009), a experimentação deve ter um papel central, não só para o ensino de Ciências, mas para as Ciências de um modo geral.

\section{A resolução de problemas e a experimentação nas Orientações Educacionais Complementares para o Ensino Médio}

Em 2002, o MEC apresentou aos professores do Ensino Médio uma nova versão do PCNEM, os PCN ${ }^{+} \mathrm{EM}$ (BRASIL, 2002). De um modo geral, este documento define a natureza do Ensino Médio e pontifica as razões que levaram o ministério a proceder à reforma. Outro fato que merece destaque é a exigência de uma maior articulação entre as áreas com a finalidade de dar maior significância aos conteúdos disciplinares trabalhados pela escola.

Contudo, de todas as competências elencadas no documento, expressão maior é dada à investigação e compreensão, no sentido de que os alunos poderão desenvolver estratégias mais consistentes para a resolução de problemas, principalmente quando é capaz de 
identificar informações e os dados que ela contém. Considera-se que elas capacitarão os estudantes a desenvolverem estratégias para enfrentamento de situações-problema (como identificar na situação-problema informações ou variáveis relevantes e estratégias de resolução). Isto é, o documento prevê que os estudantes possam, ao final do Ensino Médio, contextualizar os ensinamentos aprendidos para outras situações problemáticas semelhantes (ou não) às que ele viveu durante a sua permanência nesse ciclo de estudos.

É na reconstrução e reestruturação dos conhecimentos científicos para a construção e/ou resolução de problemas, que acreditamos na eficácia do trabalho experimental para dar o suporte necessário que esta necessita (FAGUNDES, 2007). Ao avaliarmos a experimentação como uma atividade investigativa que se sustenta em um procedimento cooperativo objetivando solucionar um problema, o mesmo pode ter um papel ímpar para um ambiente de discussão/debate de ideias sobre os melhores caminhos para se chegar rapidamente à solução.

Para que as amplitudes do ensino de Biologia tomem a dimensão de fazer com que os alunos compreendam os fenômenos biológicos em que estão envolvidos, o mesmo deve estar assente na possibilidade de gerar nos estudantes competências para agirem diante de situações adversas que enfrentem cotidianamente, tomem posição perante $\mathrm{o}$ fato, identificando o problema e promovendo a sua argumentação em prol da solução do mesmo (MARANDINO; SELLES; FERREIRA, 2009).

Logo, para que as competências acima, tão almejadas por educadores e gestores, possam ser definitivamente efetivadas nas escolas, os professores precisam caminhar em sentido oposto ao que têm percorrido durante décadas em suas aulas. Ou seja, tratar os conhecimentos de forma assimétrica, sem a devida criticidade; discutir os conteúdos de forma independente do modo de vida dos alunos, bem como tratá-los de forma propedêutica, segundo os $\mathrm{PCN}^{+} \mathrm{EM}$ (BRASIL, 2002), não tem o menor cabimento.

Espera-se que, com a conscientização dos professores sobre a importância de gerar nos estudantes as competências necessárias para compreenderem o espaço em que vivem, a disciplina Biologia e/ou Ciências possa sair do estado de latência e tome proporções robustas no sentido de instrumentalizar os educandos a agirem sobre o meio de modo judicioso e sensato (ROSITO, 2008).

Do mesmo modo, com relação às competências de "Expressão e Comunicação Articulação de Dados, Símbolos e Códigos da Ciência e da Tecnologia" que constam no documento, levando em consideração as competências destacadas anteriormente, segundo o MEC (BRASIL, 2002, p. 36-37, grifos nossos), elas necessitam desenvolver nos alunos a capacidade de

Representar dados obtidos em experimentos, publicados em livros, revistas, jornais ou documentos oficiais, na forma de gráficos, tabelas, esquemas e interpretá-los criticamente. [...] Utilizar-se de diferentes meios - observação por instrumentos ou à vista desarmada, experimentação, pesquisa bibliográfica, entrevistas, leitura de textos ou de resenhas, trabalhos científicos ou de divulgação - para obter informações sobre fenômenos biológicos, características do ambiente, dos seres vivos e de suas interações estabelecidas em seus habitats. 
Nos excertos acima, podemos observar também, a preocupação dos gestores com a questão da leitura/escrita dos estudantes em ações educativas que acontecem nas aulas de Biologia. Outro fato observável no texto diz respeito à possibilidade de a experimentação ser considerada como um mecanismo prático a serviço dos alunos para a compreensão dos fenômenos biológicos, muitas vezes desconhecidos por eles (ZULIANI et al., 2011).

Da mesma forma, na modalidade competência "Expressão e Comunicação Elaboração de Comunicações", o documento reitera que o ensino de Biologia, capacite o estudante a "elaborar comunicações orais e escritas para relatar, analisar e sistematizar eventos, fenômenos, experimentos, questões, entrevistas, visitas, correspondências" (BRASIL, 2002, p. 37, grifos nossos).

Acreditamos que o documento (BRASIL, 2002) sugere aos professores a possibilidade de perceberem a necessidade de os estudantes comunicarem para seus pares as ações pedagógicas desenvolvidas pelo grupo de alunos (desde o momento da problematização do conteúdo e/ou fenômeno, a observação empírica, o levantamento das hipóteses e seus testes de validação/negação até o estabelecimento da "verdade"), que esse é um percurso importante para os educandos, pois poderão expor seus conhecimentos utilizando linguagem específica da Biologia para descrever, com precisão e competência, o fenômeno investigado (SILVA; ZANON, 2000).

Concebido desta forma, o trabalho experimental não termina na simples experimentação e observação, mas envolve a verbalização, a negociação, o debate e a planificação de opiniões, a reflexão acerca dos procedimentos executados, a conjecturação, a avaliação criteriosa e a reflexão individual e/ou do grupo sobre o que foi feito e o que poderia ter sido melhor construído (DUSCHL; OSBORNE, 2002).

Além dos enfoques apresentados, consideramos importante destacar o extrato presente na competência "Investigação e Compreensão - Medidas, Quantificações, Grandezas e Escalas", que exalta a necessidade do estudante em "elaborar suposições e hipóteses sobre fenômenos estudados e cotejá-las com explicações científicas ou com dados obtidos em experimentos" (BRASIL, 2002, p. 39, grifos nossos).

Verificamos que os dados pontuados acima, mais uma vez, levam os estudantes a compreenderem a importância das ações experimentais na resolução de um problema. Sugerem a utilização do método científico não mais como um processo imutável e que não leva os praticantes a pensarem sobre as variáveis que incidem sobre o mesmo, mas como um procedimento em constante transformação (SILVA; MACHADO; TUNES, 2010).

\section{Outras orientações curriculares para o ensino médio}

Com relação aos conhecimentos de Biologia previstos nas Orientações Curriculares para o Ensino Médio (BRASIL, 2006), do mesmo modo que nos documentos anteriores, faz uma análise crítica sobre o ensino de Biologia que prioriza a memorização de conceitos e denominações, bem como na obrigatoriedade de reprodução de regras e processos que contribuem apenas para descaracterizar os fundamentos que norteiam a disciplina enquanto 
Ciência em transformação. Essa concepção mascara a real amplitude que a disciplina deveria proporcionar: "a formação de uma visão do homem sobre si próprio e de seu papel no mundo" (BRASIL, 2006, p. 15).

Segundo o documento, os professores deverão ter o nobre papel de desenvolver competências e habilidades em seus alunos para que os mesmos possam analisar de forma planetária o seu papel na natureza.

Trata-se, portanto, de capacitar o educando para interpretar fatos e fenômenos naturais ou não - sob a óptica da ciência, mais especificamente da Biologia, para que, simultaneamente, adquira uma visão crítica que lhe permita tomar decisões usando sua instrução nessa área do conhecimento (BRASIL, 2006, p. 20).

Diante desta necessidade, uma pergunta certamente ficará na mente dos professores: como fazer? Como sugestão para que os docentes criem as estratégias mais convenientes para a abordagem da temática que pretende implementar com seus alunos, a experimentação é sugerida, como um meio interessante, para despertar a curiosidade investigativa dos alunos (PRAIA; CACHAPUZ; GIL-PÉREZ, 2002).

Outro ponto explorado diz respeito à importância de os professores compreenderem que muitas estratégias de investigação por experimentação "podem - e devem - ser usadas, e que não são, necessariamente, dependentes de laboratórios, equipamentos sofisticados ou de atividades complexas" (BRASIL, 2006, p. 30).

Além disso, os docentes ainda precisam levar em conta a necessidade da socialização por parte dos alunos dos caminhos percorridos para chegar à conclusão. É um momento ímpar para os discentes exporem suas opiniões, defenderem seus pontos de vista e aceitarem os possíveis equívocos cometidos no transcorrer do processo experimental (LEITÃO, 2007).

\section{E as Escolas que não dispõem de laboratório?}

Nas escolas que não dispõem de laboratório, o documento sugere que o professor pode apresentar alguns dados relativos aos experimentos que pretendia realizar e pedir que os alunos apresentem suas hipóteses, construam gráficos, façam tabelas etc. Em seguida, ao expor os fundamentos teóricos e a linha de raciocínio que seguiria num procedimento experimental investigativo real, os estudantes terão condições de chegar, se não ao resultado esperado, pelo menos a construírem um perfil organizativo do pensamento acerca da situação-problema sugerida (MALHEIRO, 2009).

Ainda com relação às escolas sem laboratório, pode-se fazer uso de materiais comuns e de fácil obtenção, como um vaso de planta, um aquário ou um terrário construído a partir de garrafas pet, uma lâmpada incandescente queimada para construir uma lupa entre outros (MALHEIRO, 2016). O importante é que:

Ao organizar uma atividade prática, o professor deve valorizar o processo, explorar os fenômenos e analisar os resultados sob vários ângulos. Caso os resultados obtidos sejam diferentes dos esperados, deve aproveitar a situação para discutir o processo de produção científica. Ou seja, possibilitar ao aluno vivenciar as etapas 
do método científico. Um cuidado a ser tomado é evitar a relativização do "tudo é possível e nada é certeza". O professor pode aproveitar a atividade prática para discutir o que seriam erros de procedimento e a múltipla possibilidade de resultados e de interpretações que, às vezes, caracteriza a ciência (BRASIL, 2006, p. 31, grifo do original).

Essa visão de que os cientistas "nunca erram" e que "sabem tudo" deve ser também discutida com os alunos. Esse, sem dúvida, é um momento de aprendizado, pois os alunos precisam compreender que os cientistas são cidadãos comuns, sujeitos a erros e acertos, inclusive com muito mais erros do que acertos (CARVALHO et al., 2009).

A experimentação, além de todas as contribuições positivas que pode dar para a aprendizagem significativa dos alunos, enfatiza o comportamento crítico e criativo dos estudantes diante do processo e dos resultados alcançados, como mais um dos inúmeros objetivos da experimentação (CARVALHO, 2013).

\section{Considerações finais}

De um modo geral, as discussões realizadas neste artigo, a partir dos documentos oficiais, têm a finalidade de despertar nos professores a curiosidade e o desejo de resgatar a atividade experimental investigativa para as aulas de Ciências-Biologia, não mais no estilo da redescoberta e da receita de bolo, com a finalidade explícita de comprovar uma teoria, mas com o intuito de resolver um problema real proposto por alunos ou pelo professor.

Particularmente, consideramos esse momento de análise documental muito importante, não só pela oportunidade de os professores refletirem sobre a possibilidade dos métodos experimentais investigativos para a solução de um problema, adentrarem nas salas de aulas, pois muitos procedimentos podem ser realizados com materiais de baixo custo, que muitas vezes são encontrados na própria escola.

Por um lado, as reflexões realizadas acerca da metodologia da experimentação investigativa e da resolução de problemas, são necessárias e, muitas vezes, despertam nos professores o interesse de conhecer com mais profundidade, tais metodologias. Por outro lado, os docentes afirmaram, por exemplo, em pesquisa realizada por Malheiro (2009), que os experimentos realizados por eles em sala de aula (ou no laboratório) constam nos livros didáticos.

De um modo geral, esse procedimento não reflete apenas uma questão de "organização do texto", mas deixa transparecer a forma como os problemas são considerados pelos autores de livros didáticos (e pela editora) como instrumentos importantes para a aprendizagem. Acreditamos que esse proceder pode inibir a capacidade que os alunos têm de buscar as informações que necessitam em fontes diversas, pois acaba por acostumá-los apenas a voltar algumas páginas do capítulo para encontrar a resposta certa explícita no texto.

Nesse sentido, uma forma de tornar as atividades experimentais mais motivadoras para os escolares, seria concebê-las como um passo importante do caminho que deve ser trilhado para se chegar à conclusão de um problema. As experimentações, quando colocadas 
no término do capítulo, não são nem consideradas nem apresentadas aos estudantes como "problemas", mas apenas têm a função de confirmar uma teoria (MALHEIRO, 2009).

Com relação a esses "problemas" que constam nos manuais, é necessário que os professores tenham clareza que, na maioria das vezes, eles não passam de simples "exercícios", pois quando fazemos uso de problemas verdadeiros, geralmente, não temos a resposta, muito menos sabemos se ela realmente existe. Este fato vai contra ao que se observa nos livros didáticos, que oferecem somente "exercícios", pois os estudantes encontram todas as informações que necessitam no corpo do texto (resolução mecânica) e, frequentemente, apresentam apenas um tipo de solução.

É significante, na proposição de um problema, que este o seja também para o professor, pois se assim não for, isto é, se o docente já conhece a princípio seu resultado, voluntária ou involuntariamente, poderá fornecer dados que resolverão facilmente o problema, retirando dos resolventes a curiosidade e o interesse pela questão. Nessa perspectiva, apesar de os professores saberem claramente como e onde pretendiam chegar ao realizar uma experimentação investigativa para a resolução de um problema, eles não diziam abertamente aos alunos que deveriam buscar formas adequadas e instrumentos apropriados para que pudessem confirmar (ou negar) suas percepções acerca do problema.

Portanto, acreditamos que os documentos oficiais deveriam ser mais específicos, no sentido de apresentar aos professores, indicações claras de como poderiam deixar suas aulas nas perspectivas anunciadas nos diplomas oficiais. Outrossim, deveriam disponibilizar aos professores, sítios na internet e materiais impressos, orientações práticas a serem desenvolvidas com materiais alternativos no ambiente da sala de aula.

\section{Referências}

ALMEIDA, Willa Nayana Corrêa. A argumentação e a experimentação investigativa no ensino de matemática: o problema das formas em um clube de ciências. 2017. $109 \mathrm{f}$. Dissertação (Mestrado Profissional em Educação em Ciências e Matemáticas) - Universidade Federal do Pará, Belém, PA, 2017.

BOGDAN, Robert; BIKLEN, Sari Knopp. Investigação qualitativa em educação. Porto: Porto Editora, 1994.

BRASIL. Secretaria de Educação Fundamental. Parâmetros Curriculares Nacionais: Ciências Naturais. Secretaria de Educação Fundamental. Brasília: MEC/SEF, 1997a.

BRASIL. Secretaria de Educação Média e Tecnológica. Parâmetros Curriculares Nacionais: Ensino Médio. Parte III: Ciências da Natureza, Matemática e suas Tecnologias. Secretaria de Educação Média e Tecnológica. Brasília: MEC/SEMT, 1997 b.

BRASIL, Secretaria de Educação Média e Tecnológica. PCN+ Ensino Médio: orientações educacionais complementares aos Parâmetros Curriculares Nacionais. Ciências da Natureza, Matemática e suas Tecnologias. Brasília: MEC/SEMTEC, 2002. 
BRASIL. Secretaria de Educação Básica. Ciências da Natureza, Matemática e suas Tecnologias. Orientações Curriculares para o Ensino Médio. v. 2. Brasília: Ministério da Educação, Secretaria de Educação Básica, 2006.

CARVALHO, Ana Maria Pessoa de et al. Ciências no ensino fundamental: o conhecimento físico. São Paulo: Scipione, 2009.

CARVALHO, Ana Maria Pessoa de. O ensino de ciências e a proposição de sequências de ensino investigativas. In: CARVALHO, Ana Maria Pessoa de (org.) Ensino de Ciências por Investigação: condições para implementação em sala de aula. São Paulo: Cengage Learning, 2013, p. 1-20.

DENZIN, Norman K.; LINCOLN, Yvonna S. O planejamento da pesquisa qualitativa: teorias e abordagens. 2 ed. Porto Alegre: Ed. Artmed, 2006.

DUSCHL, Richard A.; OSBORNE, Jonathan. Supporting and promoting argumentation discourse in science education. Studies in Science Education, v. 38, n. 1, p. 39-72, 2002.

FAGUNDES, Suzana Margarete Kurzmann. Experimentação nas aulas de ciências: um meio para a formação da autonomia? In: GALIAZZI, Maria do Carmo et al (org.). Construção curricular em rede na educação em ciências: uma aposta de pesquisa na sala de aula. 1 ed. Ijuí: Unijuí, 2007, p. 317-336.

FRANCISCO JÚNIOR, Wilmo E.; FERREIRA; Luiz Henrique; HARTWIG, Dácio Rodney. Experimentação problematizadora: fundamentos teóricos e práticos para a aplicação em sala de aula de ciências. Química nova na escola. São Paulo, n. 30, p. 34-41, nov. 2008.

GASPAR, Alberto. Experiências de Ciências para o Ensino Fundamental. São Paulo: Ática, 2009.

KRASILCHIK, Myriam. Prática de Ensino de Biologia. 4. ed. São Paulo: Editora USP, 2008.

LEITÃO, Selma. Processos de construção do conhecimento: a argumentação em foco. ProPosições. Campinas, v. 18, n. 3, p. 75-92, set./dez. 2007.

LOPES, José Bernardino. A resolução de problemas em física e química: modelo para estratégias de ensino-aprendizagem. Lisboa: Texto Editora, 1994.

LORENZATO, Sergio. Para aprender matemática. 3. ed. Campinas/SP: Autores associados, 2010.

MALHEIRO, João Manoel da Silva. A resolução de problemas por intermédio de atividades experimentais investigativas relacionadas à biologia: uma análise das ações vivenciadas em um curso de férias em Oriximiná (PA). 2009. 314 f. Tese (Doutorado em Educação para Ciência) - Faculdade de Ciências, Universidade Estadual Paulista, Bauru, SP, 2009. 
MALHEIRO, João Manoel da Silva. Atividades experimentais no ensino de ciências: limites e possibilidades. Actio: Docência em Ciências. Curitiba, v. 1, n. 1, p. 108-127, jul./dez. 2016.

MARANDINO, Martha; SELLES, Sandra Escovedo; FERREIRA, Marcia Serra. Ensino de Biologia: histórias e práticas em diferentes espaços educativos. São Paulo: Cortez, 2009.

MERRIAM, Sharan B. Qualitative Research and Case Study Applications in Education. San Francisco: Jossey-Bass Publishers, 1998.

PRAIA, João; CACHAPUZ, António; GIL-PÉREZ, Daniel. A hipótese e a experiência científica em educação em ciência: contributos para uma reorientação epistemológica. Ciência \& Educação. Bauru, v. 8, n. 2, p. 253-262, 2002.

RICARDO, Elio Carlos; ZYLBERSZTAJN, Arden. As ciências no ensino médio e os parâmetros curriculares nacionais: da proposta à prática. Ensaio: Avaliação e Políticas Públicas em Educação. Rio de Janeiro, v. 10, n. 35, p. 141-160, abr./jun. 2002.

RICARDO, Elio Carlos; ZYLBERSZTAJN, Arden. Os Parâmetros Curriculares Nacionais na formação inicial de professores das ciências da natureza e matemática do ensino médio. Investigações em ensino de ciências. Porto Alegre, v. 12, n. 2, p. 339-355, 2007.

ROSITO, Berenice Alvares. O ensino de ciências e a experimentação. In: MORAES, Roque (org.). Construtivismo e ensino de ciências: reflexões epistemológicas e metodológicas. 3 ed. Porto Alegre: EDIPUCRS, 2008. p. 195-208.

SERRANO, Gloria Pérez. Investigación cualitativa. Retos e interrogantes - I. Métodos. Madrid: Ed. La Muralla, 2004.

SILVA, Deolinda Rosa Camarinha. Políticas e práticas curriculares na biologia e geologia: um estudo situado numa escola secundária. 2010. Tese (Doutorado em Ciências da Educação) - Universidade do Porto, 2010.

SILVA, Roberto Ribeiro da; MACHADO, Patrícia Fernandes Lootens; TUNES, Elizabeth. Experimentar sem medo de errar. In: SANTOS, Wildson Luiz P. dos; MALDANER, Otavio Aloisio (org.). Ensino de Química em foco. 1 ed. Ijuí: Unijuí, 2010. p. 231-261.

SILVA, Leonice Heloísa; ZANON, Lenir Basso. Experimentação no ensino de ciências. In: SCHNETZER, Roseli Pacheco; ARAGÃO, Rosália Maria Ribeiro (org.) Ensino de Ciências: fundamentos e abordagens. 1 ed. Campinas: R Vieira Gráfica e Editora Ltda, 2000. p. $120-153$.

VALLES, Miguel S. Técnicas Cualitativas de Investigación Social. Reflexión metodológica y práctica profesional. Madrid: Editorial SÍNTESIS, S.A., 1997.

ZULIANI, Silvia Regina Quijadas Aro et al. O experimento investigativo e as representações de alunos de ensino médio como recurso didático para o levantamento e análise de obstáculos epistemológicos. In: V Encontro Regional Sul de Ensino de Biologia (EREBIOSUL). Londrina: UEL, 2011. 


\section{Agradecimentos}

Ao Programa PNPD-CAPES e aos colegas professores do Grupo de Estudo, Pesquisa e Extensão FormAÇÃO de Professores de Ciências da Universidade Federal do Pará, Campus Castanhal. 